\title{
Effects of Light Quality and Chemical Elicitors on the Growth Parameters and Rosmarinic Acid Content of in vitro Cultures of Hyptis pectinata (L.) Poit.
}

\author{
Rita C. N. Pedroso, ${ }^{a, b}$ Leticia P. Pimenta, ${ }^{b}$ Marcos G. Tozatti, ${ }^{b, c}$ Núbia A. A. Branquinho, ${ }^{a}$ \\ Alessandra C. B. A. M. Hara, ${ }^{a}$ Fernando H. L. Silva, ${ }^{a}$ Alan C. Costa, ${ }^{a}$ Fabiano G. Silva, ${ }^{a}$ \\ Carlos E. S. Miranda, ${ }^{d}$ Marcio L. A. Silva, ${ }^{\circledR b}$ Wilson R. Cunha, ${ }^{b}$ Patricia M. Pauletti ${ }^{\circ} b$ \\ and Ana H. Januario ${ }^{\circledR} * b$
}

aInstituto Federal de Educação, Ciência e Tecnologia Goiano, Câmpus Rio Verde, 75901-970 Rio Verde-GO, Brazil

${ }^{b}$ Núcleo de Pesquisa em Ciências Exatas e Tecnológicas, Universidade de Franca, 14404-600 Franca-SP, Brazil

${ }^{c}$ Fundação Educandário Pestalozzi, 14401-080 Franca-SP, Brazil

${ }^{d}$ Curso de Ciências Farmacêuticas, Universidade de Ribeirão Preto, 14096-900 Ribeirão Preto-SP, Brazil

\begin{abstract}
Hyptis pectinata (L.) Poit is a folk medicinal species in Northeast Brazil. In this work, seedlings of $H$. pectinata were cultured in vitro under diverse light quality spectra and under the influence of two distinct chemical elicitors, salicylic acid and silver nitrate (SN), at concentrations of 30 and $60 \mu \mathrm{M}$. Growth parameters, biomass and rosmarinic acid (RA) content were evaluated. RA may be associated with the functional properties of this plant. In the light quality experiments, the highest level of rosmarinic acid was found under red light $\left(161.65 \pm 8.64 \mu \mathrm{g} \mathrm{g}^{-1} \mathrm{DW}\right.$ (dry weight)) at 20 days (4.26-fold higher than the control white light). Among the evaluated elicitors, elicitation with $60 \mu \mathrm{M}$ SN at 3 days and $30 \mu \mathrm{M} \mathrm{SN}$ at 6 days favored the highest rosmarinic acid content $\left(6361.70 \pm 216.96\right.$ and $4542.98 \pm 92.53 \mu \mathrm{g} \mathrm{g}^{-1} \mathrm{DW}$, respectively), with relatively high biomass yield and a similar number of leaves and height as those of control seedlings. This approach is new for $H$. pectinata.
\end{abstract}

Keywords: Hyptis pectinata, rosmarinic acid, in vitro culture, light quality, chemical elicitors

\section{Introduction}

The genus Hyptis Jacq. is one of the main genera of the family Lamiaceae, it has approximately 400 species with a wide distribution, and it occurs mainly in tropical and subtropical regions of the Americas and Africa. According to Harley and Pastore, ${ }^{1}$ Brazil is the main diversity center for Hyptis, with the occurrence of species, especially in the Atlantic Rain Forest and Cerrado, being 69\% endemic. Species of the genus Hyptis have outstanding economic importance in the food, cosmetic and pharmaceutical industries due to their essential oils. ${ }^{2,3}$

In folk medicine, Hyptis pectinata (L.) Poit., popularly known in Northeast Brazil as "Sambacaita" or "Canudinho", has been reported in colic and liver diseases, ${ }^{3}$ rhinopharyngitis, nasal congestion, skin diseases, gastric disorders, pain, fever, and bacterial and fungal infections. ${ }^{4,5}$

*e-mail: anahjanuario@gmail.com
The chemical constituents previously characterized from $H$. pectinata include monoterpenes, sesquiterpenes, triterpenes, lactones, phenylpropanoids and flavonoids. ${ }^{2,6-9}$

Falcão et al. ${ }^{10}$ determined that rosmarinic acid (RA) is a major constituent associated with the antinociceptive effects of the ethyl acetate fraction obtained from the leaves of $H$. pectinata. RA, an ester of caffeic acid and 3,4-dihydroxyphenyllactic (Figure 1), was initially isolated from Rosmarinus officinalis and is one of the main phenolic compounds in sweet basil (Ocimum basilicum L.). ${ }^{11,12}$ This phenolic acid has been demonstrated to have significant<smiles>O=C(/C=C/c1ccc(O)c(O)c1)OC(Cc1ccc(O)c(O)c1)C(=O)O</smiles>

Figure 1. Chemical structure of rosmarinic acid (1). 
adstringent, antioxidant, anti-inflammatory, antimutagenic antibacterial and antiviral potential. ${ }^{13}$

Essential oils of Hyptis are an important source of active biomolecules and insecticidal activity. Essential oils have been used in the control of leaf cutting ants, ${ }^{2}$ and the insecticidal activity of $H$. marrubioides essential oil has been used in the control of the bean worm Zabrotes subfasciatus. ${ }^{14}$

Studies aiming to improve the planting, growth and propagation of plant species are extremely important for the preservation of species of interest; in this context, micropropagation stands out as a conservation strategy to maintain the diversity of this species. ${ }^{15}$

Light is one of the main environmental abiotic elicitors for plants, affecting the growth, morphology, biomass, and, especially, secondary metabolite biosynthesis. ${ }^{16}$ For this reason, studies to better understand the influence of the different light spectra on plants to optimize plant production and quality have been a major research target in recent years. ${ }^{16-18}$ Abiotic elicitors, including UV irradiation, heavy metal stress, light source, and chemical elicitors, are also widely used with in vitro propagation approaches to increase the production of a desired natural product or even to improve plant development and growth. ${ }^{19-21}$

Our research group has focused on optimization of the micropropagation of species of Hyptis. In previous studies, we investigated $H$. marrubioides microplants inoculated with fungi and bacteria, ${ }^{22}$ how flavonoid production by $H$. marrubioides is affected by light quality ${ }^{23}$ and exogenous elicitors salicylic acid and silver nitrate. ${ }^{24}$ However, no studies have investigated the influence of light and chemical elicitors on $H$. pectinata. Therefore, in this work, we aimed to study the effects of light quality and chemical elicitors on the parameters of growth and the accumulation of the major specialized metabolite, rosmarinic acid, aspiring to confer resistance to this medicinal species as well as to offer a tool for its preservation.

\section{Experimental}

Plant material

$H$. pectinata seedlings previously established by in vitro germination of seeds were obtained from the greenhouse at the Plant Tissue Culture Laboratory of the Federal Institute Goiano, Rio Verde Campus, Goiás, Brazil. The species Hyptis pectinata (L.) Poit (synonym: Mesosphaerum pectinatum (L.) Kuntze) was identified by Dr Gisele Cristina de Oliveira Menino, and a voucher specimen has been deposited in the Herbarium at the Federal Institute of Goiás, Rio Verde Campus under record number 492.

\section{In vitro culture conditions}

The seeds were surface-sterilized with two systemic fungicides, 0.25 Bendazol (carbendazin) and 0.2\% Alterno (tebuconazole), for $1 \mathrm{~h}$, followed by treatment with $1 \%$ sodium hypochlorite for $30 \mathrm{~min}$, and the seeds were rinsed thrice with sterile distilled water. Next, seeds were germinated and maintained on Murashige and Skoog ${ }^{25}$ medium supplemented with $30 \mathrm{~g} \mathrm{~L}^{-1}$ of sucrose and solidified with agar at $3.5 \mathrm{~g} \mathrm{~L}^{-1}$. The $\mathrm{pH}$ was adjusted to 5.8 before autoclaving. The cultures were incubated in a growth chamber for 30 days at $50 \mu \mathrm{mol} \mathrm{m} \mathrm{m}^{-2} \mathrm{~s}^{-1}$ photosynthetically active radiation (PAR), at an average temperature of $23 \pm 1{ }^{\circ} \mathrm{C}$ and a photoperiod of $16 \mathrm{~h}$. Thereafter, the seedlings were subcultured on the same medium and maintained in a growth room for 10 days at $50 \mu \mathrm{mol} \mathrm{m} \mathrm{m}^{-2} \mathrm{~s}^{-1}$ PAR, $23 \pm 1^{\circ} \mathrm{C}$ and 16-h photoperiod. All experiments were carried out in glass flasks containing $50 \mathrm{~mL}$ of semisolid medium with five seedlings per flask. The seedlings were exposed to light quality tests and chemical elicitors in independent experiments.

\section{Light quality experiments}

After 10 days, the seedlings were transferred to a chamber and exposed to continuous irradiation of different light spectra: white $(300-750 \mathrm{~nm})$, blue $(400-490 \mathrm{~nm})$, green (490-560 nm), red (600-700 nm), and yellow (560-590 nm) using a TP 40W Taschibra® fluorescent lamp (Indaial, Santa Catarina, Brazil) with a radiance of $50 \pm 5 \mu \mathrm{mol} \mathrm{m} \mathrm{m}^{2} \mathrm{~s}^{-1}$ under a photoperiod of $16 \mathrm{~h}$. Spectral quality was determined using a USB2000 spectroradiometer (Ocean Optics Dudedin, FL, USA), and the light intensity was adjusted using a PAR sensor (QSO-S model, Decagon Devices, Pullman, WA, USA). The cultures were evaluated after 20 and 30 days of light exposure. Cultures grown under white light were used as a control. The light chambers were sealed with a black cloth to avoid light interference.

\section{Light quality biometric analyses}

After 30 days of growth in the light chamber, the seedlings were removed from the flasks, and the plants were evaluated for fresh weight, shoot length, and number of leaves per seedling. The experimental design was completely randomized using a $5 \times 2$ factorial arrangement (5 types of light sources $\times 2$ periods of evaluation). The plants were dried in a forced-air oven at $35^{\circ} \mathrm{C}$ to a constant weight and then weighed to obtain the dry weight (DW). For weight measurements, whole seedlings without roots were considered. 


\section{Elicitation treatments}

The elicitation treatments consisted of the use of two exogenous elicitors, salicylic acid (SA) and silver nitrate (SN), at two different concentrations (30 and $60 \mu \mathrm{M})$. The choice of these concentrations was based on data from the literature ${ }^{21}$ and previous experiments conducted by our research group with a species of $H$. marrubiodes. ${ }^{24}$ Treatment I: the plants were subcultured in glass flasks containing $50 \mathrm{~mL}$ of Murashige-Skoog medium for 10 days; after this time, the seedlings were placed in a new flask containing MS medium and the desired elicitor for 20 days. For treatment II, the plants were subcultured in MS medium as described in treatment I for 20 days. Then, the selected elicitor was added to the cultures at the desired concentration and allowed to remain in contact with the medium for three or six days.

\section{Elicitation biometric analyses}

Four flasks with five explants each were used for each treatment, totaling 20 flasks and 100 plants in both treatments (I and II), including the control group. The control plants were placed in fresh MS medium without elicitor. In these experiments, the plants were maintained in a growth room at $23 \pm 1{ }^{\circ} \mathrm{C}$ under a 16 -hour photoperiod. After treatments, the plants were harvested, and the growth parameters (shoot length, expanded leaf number, and fresh mass) were measured. The biomass was dried in a forced air oven at $35^{\circ} \mathrm{C}$ until a constant weight was achieved to obtain the dry weight.

\section{Chemical analyses}

The rosmarinic acid content in $H$. pectinata dry seedlings was evaluated by high-performance liquid chromatography-diode array detection (HPLC-DAD). For sample preparation, $200 \mathrm{mg}$ of dried seedlings cultured in vitro was extracted with $4 \mathrm{~mL}$ of HPLC-grade methanol by ultrasonic-assisted extraction (30 min), after filtration with $0.2 \mu \mathrm{m}$ PTFE (polytetrafluoroethylene) membrane and transferred to a $1 \mathrm{~mL}$ vial. This procedure was performed in triplicate. For quantitative analyses, a standard curve was plotted for different concentrations (0.00063 to $0.5 \mathrm{mg} \mathrm{mL}^{-1}$ ) of rosmarinic acid in methanol (HPLC grade, J.T Baker, Phillipsburg, USA); each point was measured in triplicate. The obtained regression equation was $y=4.0 \times 10^{7} x-99476$, with a correlation coefficient $\left(\mathrm{R}^{2}\right)$ of 0.9997 . The rosmarinic acid was acquired from the standards bank of the Natural Products group of the University of Franca, being previously isolated from Rosmarinus officinalis as described by Bernardes et al. ${ }^{26}$ The spectral data were consistent with previously published data. ${ }^{27}$ The HPLC analyses were performed using a Shimadzu Prominence LC-20AD binary system equipped with a DGU-20A5 degasser, an SPD-20A series diode array detector, a CBM-20A communication bus module, an SIL-20A HT autosampler, and a CTO-20A column oven (Shimadzu). The Gemini ODS column $(250 \times 4.6 \mathrm{~mm}, 5 \mu \mathrm{m}$; Phenomenex) was equipped with a precolumn, and the mobile phase was $\mathrm{CH}_{3} \mathrm{OH} / \mathrm{H}_{2} \mathrm{O} / \mathrm{HCOOH}$ (5:94.8:0.2, v/v/v) in a linear gradient until $100 \% \mathrm{CH}_{3} \mathrm{OH}$ for $30 \mathrm{~min}$, followed by 10 -min elution with $100 \% \mathrm{CH}_{3} \mathrm{OH}$. A total of $20 \mathrm{~min}$ was used to return to baseline conditions. The flow rate was

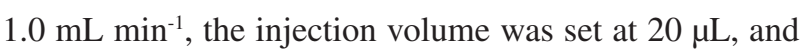
UV detection was set at $254 \mathrm{~nm}$ and $40^{\circ} \mathrm{C}$. Data acquisition was performed using a computer.

Nuclear magnetic resonance (NMR) and mass spectrometry (MS) analysis

${ }^{1} \mathrm{H}$ and ${ }^{13} \mathrm{C}$ NMR spectra for RA (1) were recorded in dimethyl sulfoxide- $d_{6}$ on a Bruker® DRX-500 spectrometer using tetramethylsilane (TMS) as the internal standard. The electrospray ionization (ESI) mass spectrometry analyses were performed in a micrOTOF Q II, ESI-TOF Mass Spectrometer (Bruker Daltonics, Billerica, MA, USA) by direct infusion. Experimental conditions: capillary voltage $3.5 \mathrm{kV}$, nitrogen was used as drying (temperature $180^{\circ} \mathrm{C}$, and flow of $4 \mathrm{~L} \mathrm{~min}^{-1}$ ) and as the nebulizer gas (pressure of 0.4 bar). Internal calibration was performed with $10 \mathrm{mg} \mathrm{mL}^{-1}$ sodium trifluoroacetate (Na-TFA) solution, and the capillary voltage was set to $3500 \mathrm{~V}$.

\section{Statistical analyses}

For chemical analysis, the samples were prepared in triplicate. The numerical data were statistically evaluated using software $\mathrm{R}$ version 3.5.2, ${ }^{28}$ Agricolae package, followed by Tukey's test (5\%) for comparison of means. The figures were generated using Sigma Plot ${ }^{\circledR} 11.0$ software. ${ }^{29}$

\section{Results and Discussion}

\section{Light quality}

In addition to being the primary energy source for plant life through photosynthesis, light regulates many aspects of plant growth and development, including photomorphogenesis. ${ }^{30}$ Distinct wavelengths of light are detected by multiple plant photoreceptors. UV-B radiation 
is perceived by UV Resistance Locus 8 (UVR8), UV-A and blue radiation are perceived by phototropins (phots) and cryptochromes (CRYs), and red and far-red are mediated by phytochromes (phy), each resulting in a different response by the plant. ${ }^{31,32}$ The quality of light can even regulate the biosynthesis of endogenous hormones including gibberellins (GAs), the auxin indoleacetic acid (IAA), cytokinins (CKs), and abscisic acid (ABA), consequently influencing secondary metabolism. Furthermore, the effects of light quality vary according to plant species. ${ }^{17,33}$

The results obtained in the light quality experiments on H. pectinata are shown in Figures 2-4. Statistical analyses did not show significant differences in the average of number of expanded leaves with 20 days of exposure to different light quality (Figure 2). However, at thirty days, the number of leaves was reduced 1.59-fold compared to control white light (19.48 \pm 7.30 leaves). The seedlings were taller compared to the control at 20 and 30 days. The highest value for shoot length was found for plants exposed to blue light: $11.87 \pm 3.53 \mathrm{~cm}$ at 20 days and $15.47 \pm 3.87 \mathrm{~cm}$ at 30 days ( 1.66 and 1.78 -fold higher than the control seedlings, respectively).

Fresh and dry weights at 20 days were not influenced by the light source. In contrast, at 30 days, plants grown under red light had 1.32-fold higher fresh weight $(0.56 \pm 0.17 \mathrm{~g})$ compared to the control (Figure 3).

The level of rosmarinic acid (RA) present in H. pectinata seedling extracts was determined by HPLC-DAD analysis (Figure 4). The rosmarinic acid content in seedlings grown under white light was lower than the limit of quantification $(\mathrm{LOQ}=0.761 \mu \mathrm{g} \mathrm{mL}-1)$ with these analytical conditions. In the two periods evaluated, different light quality resulted in enhanced RA content, except for green and blue light. The highest accumulation was found under red (161.65 $\left.\pm 8.64 \mu \mathrm{g} \mathrm{g}^{-1} \mathrm{DW}\right)$ and yellow $\left(82.82 \pm 3.29 \mu \mathrm{g} \mathrm{g}^{-1} \mathrm{DW}\right)$ light during the 20-day cultivation period (4.26 and 2.18-fold higher than the control, respectively). Light exposure for 20-days promoted the highest RA yield, especially red light, which resulted in a rosmarinic acid content 7.45 -fold higher than at 30 days of culture.

The influence of light quality on the production of rosmarinic acid, together with the evaluated growth parameters, indicates that red light favors the highest concentration of this metabolite at 20 days of exposure despite the decrease in the number of leaves, the height of the plant and the yield of fresh and dry biomass. The enzyme phenylalanine ammonia lyase (PAL), which
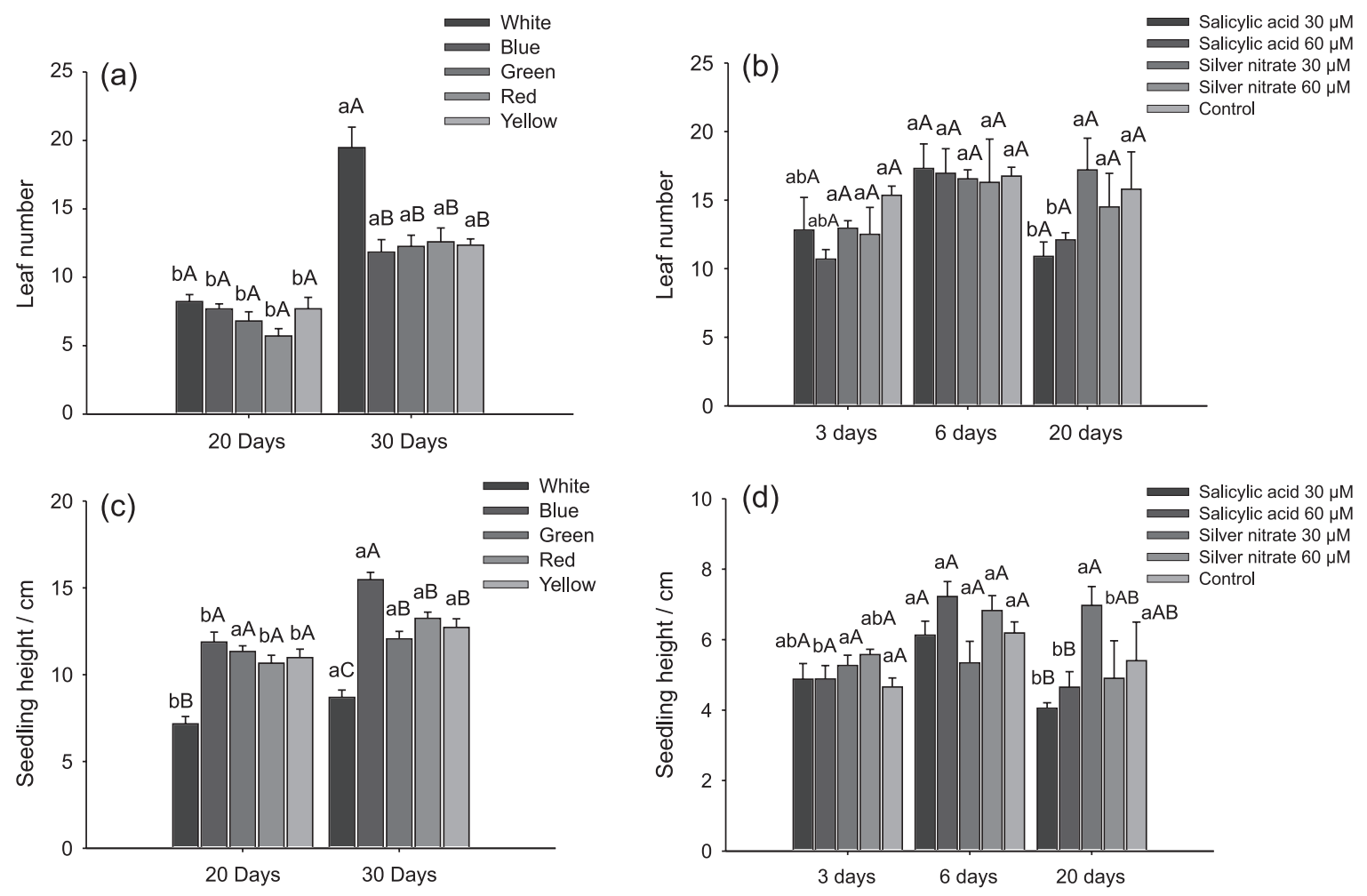

Figure 2. Average of number of (a,b) expanded leaves and (c,d) seedling height of $H$. pectinata seedlings under treatment with different light quality or chemical elicitors. Lowercase letters compare data averages among times (days), and uppercase letters compare data averages within each time. Means followed by the same letter indicate that there was no significant difference according to Tukey's test at $5 \%$ probability. 

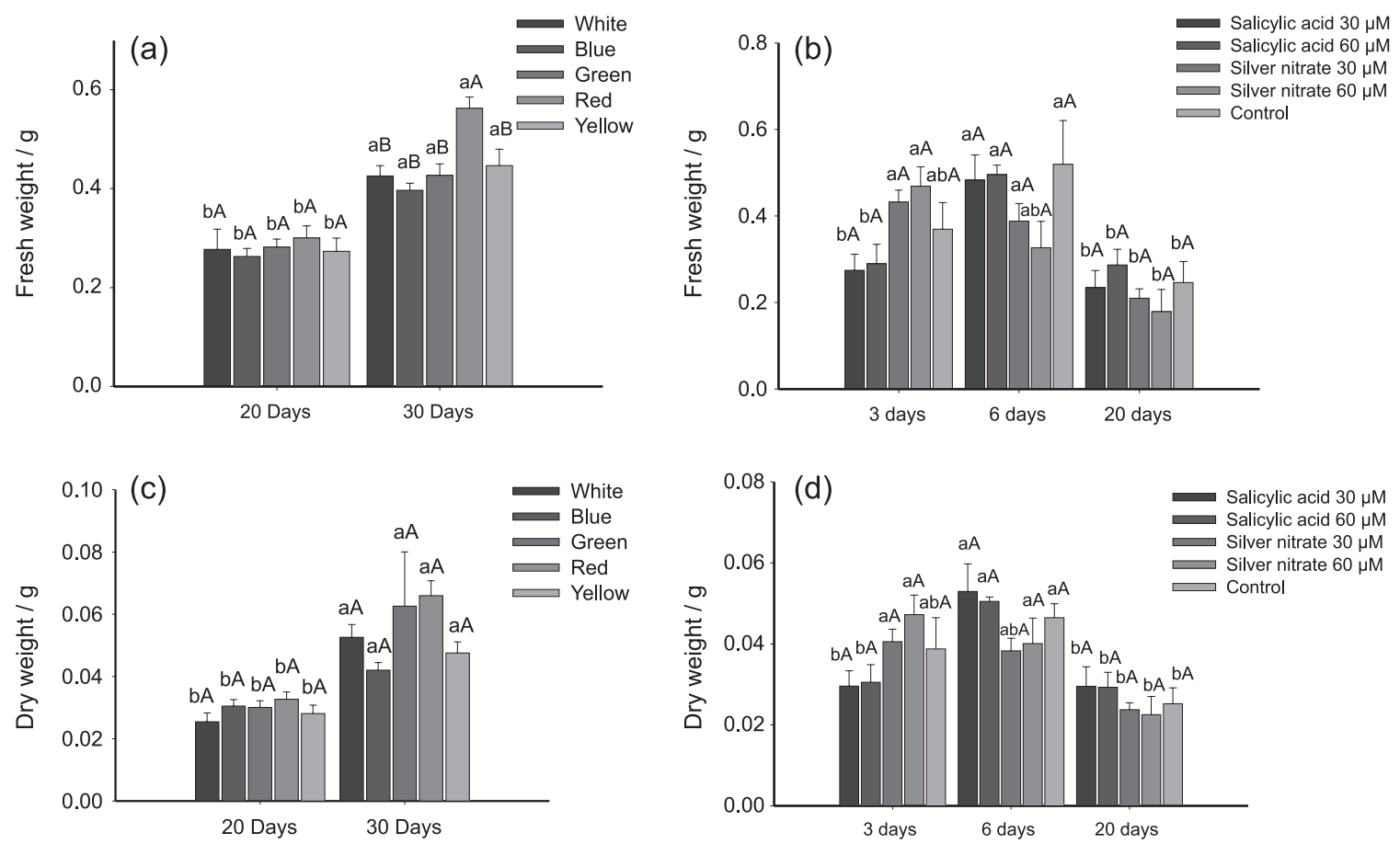

Figure 3. Average (a,b) fresh and (c,d) dry weights of $H$. pectinata seedlings in light quality and chemical elicitor experiments. Lowercase letters compare data averages among times (days), and uppercase letters compare data averages within each time. Means followed by the same letter indicate that there was no significant difference according to Tukey's test at $5 \%$ probability.
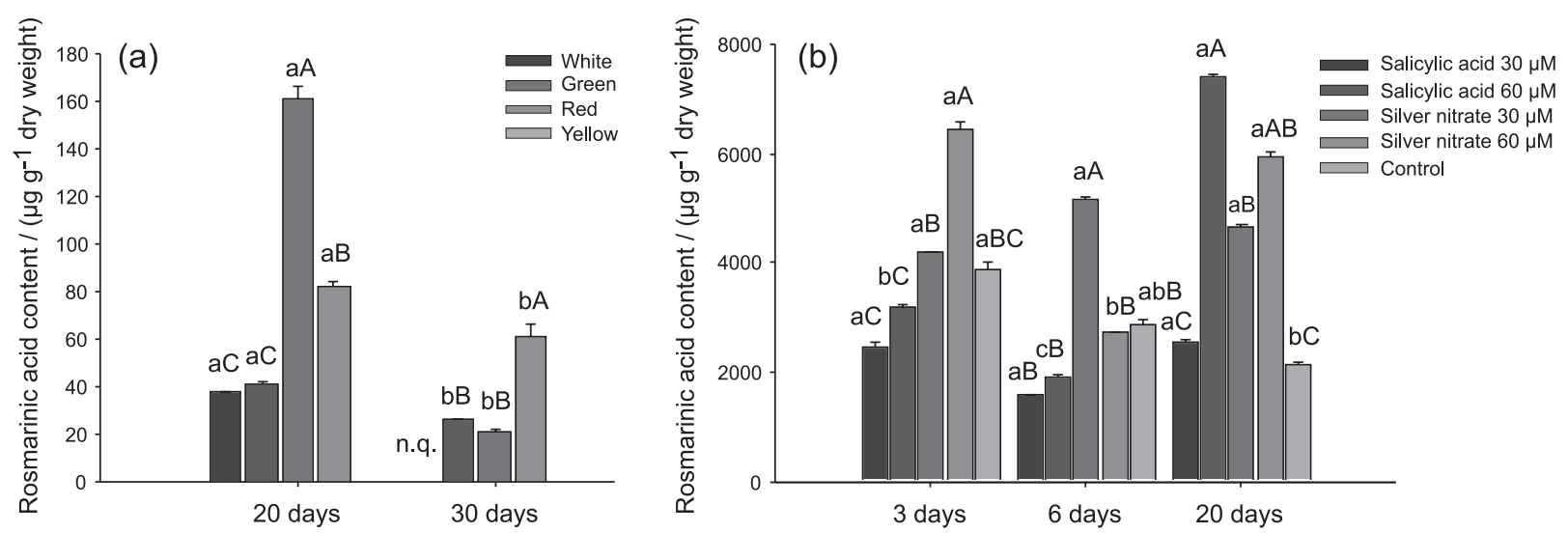

Figure 4. Rosmarinic acid content in methanolic extracts of $H$. pectinata seedlings in (a) light quality and (b) chemical elicitor experiments. Lowercase letters compare data averages among times (days), and uppercase letters compare data averages within each time. Means followed by the same letter indicate that there was no significant difference according to Tukey's test at $5 \%$ probability. n.q. $=$ not quantified.

catalyzes the deamination of phenylalanine into cinnamic acid, is stimulated by red and UV radiation, thus enhancing the production of phenolic compounds. ${ }^{34}$ Therefore, our results suggest that the appropriate light quality may favor the phenylpropanoid pathway, inducing RA biosynthesis. Shiga et al. ${ }^{11}$ showed that red and white light irradiation induces RA accumulation up to a level of $6 \mathrm{mg} \mathrm{g}^{-1}$ in sweet basil, Ocimum basilicum L. (Lamiaceae). ${ }^{11}$ In a recent work, Stagnari et al. ${ }^{35}$ found that the application of yellow, green or blue colored plastic films lowered the rosmarinic acid content on average by $29.8 \%$ compared to control treatment (white light) in basil plants cultured in a greenhouse. In contrast to our results, extracts from shoot cultures of Aronia melanocarpa, A. arbutifolia and A. $\times$ prunifolia showed greater variation in the amounts of RA, with maximum amounts found in extracts from shoots cultured in the presence of blue light. ${ }^{36}$

RA and its methyl ester have been described as antimicrobial components of the hydromethanolic extract of H. atrorubens, ${ }^{37}$ but this is the first report of the importance 
of light quality on the production of rosmarinic acid in $H$. pectinata in vitro cultures.

\section{Chemical elicitors}

An elicitor can be defined as a factor, molecule or agent that, when incorporated in a cellular system, is able to improve the biosynthetic competence of specific compounds of a secondary metabolism pathway. Elicitors communicate with receptors present on the plasma membrane of plant cells, stimulating an array of responses. In general, widely used chemical elicitors or signaling compounds include jasmonic acid (JA), methyl jasmonate (MeJA), salicylic acid (SA), acetyl salicylic acid (ASA), ethylene (ET), heavy metals (HM), nitric oxide (NO), and synthetic chemicals. ${ }^{20}$

In this work, salicylic acid and silver nitrate were selected as abiotic elicitors to be incorporated in the $H$. pectinata in vitro cultures since they have different mechanisms of action. SA is a phytohormone recognized to induce systemic acquired resistance (SAR) to many pathogens, whereas $\mathrm{SN}$ is associated with interference in ethylene biosynthesis. ${ }^{20,38}$

The effect of the abiotic elicitors SA and SN at the two concentrations evaluated ( 30 and $60 \mu \mathrm{M})$ in comparison to the control are shown in Figures 2 to 4.

There was no statistically significant difference in the number of expanded leaves among plants treated with the elicitors in the three times evaluated, except for SA after 20 days of cultivation, which had a reduced number of leaves (1.45-fold, $30 \mu \mathrm{M}$ and 1.31-fold fewer at $60 \mu \mathrm{M}$ ) compared to the control. Likewise, SA significantly reduced the average height of seedlings after 20 days of treatment. The highest values for fresh and dry biomass were obtained at 6 days of cultivation, regardless of the type of elicitor or concentration evaluated (Figures 2 and 3).

Concerning RA production, the quantity of RA was significantly higher in the presence of $60 \mu \mathrm{M} \mathrm{SN}$ (1.65-fold), $30 \mu \mathrm{M} \mathrm{SN}$ (1.57-fold) and $60 \mu \mathrm{M} \mathrm{SA}$ (3.45-fold) compared to the control at 3, 6 and 20 days, respectively. This was in contrast with $30 \mu \mathrm{M} \mathrm{SA}$, which resulted in the lowest level of RA accumulation at the three periods evaluated (Figure 4).

Analyzing the RA production and the three parameters of growth together, elicitation with $60 \mu \mathrm{M}$ SN for 3 days and $30 \mu \mathrm{M}$ SN for 6 days favored the highest RA content $\left(6361.70 \pm 216.96\right.$ and $\left.4542.98 \pm 92.53 \mu \mathrm{g} \mathrm{g} \mathrm{g}^{-1} \mathrm{DW}\right)$ while maintaining the number of leaves, the height of the seedlings, and the yield of fresh and dry biomass.

With a comparative analysis of two factors affecting $H$. pectinata, light quality and abiotic elicitors, it was found that, in general, the abiotic elicitor SN intensified the accumulation of rosmarinic acid without changing the parameters of growth and biomass at appropriate concentrations and culture times. Additionally, the highest concentration of RA was obtained with $60 \mu \mathrm{M}$ of the elicitor SA at 20 days $\left(7402.95 \pm 109.18 \mu \mathrm{g} \mathrm{g}^{-1} \mathrm{DW}\right)$, which was 47.09-fold greater than the highest content obtained in the light quality experiments with red light at the same culture time $\left(161.65 \mu \mathrm{g} \mathrm{g}^{-1} \mathrm{DW}\right)$.

Li et al..$^{39}$ described the effect of SA in Salvia miltiorrhiza suspension cells, in which the gene expression of tyrosine aminotransferase (TAT), phenylalanine ammonialyase (PAL), and rosmarinic acid synthase (RAS) were upregulated. As a result, there was increased accumulation of phenolic acids, including RA. In another study, Park et al..$^{40}$ showed that $\mathrm{SN}$ at 20 and $30 \mathrm{mg} \mathrm{L}^{-1}$ induced the expression of phenylpropanoid biosynthetic genes and increased the accumulation of rosmarinic acid in Agastache rugosa cell culture to 1.64 and $2.94 \mathrm{mg} \mathrm{g}^{-1}$, respectively, 10.12-fold higher than content in nontreated controls.

The abiotic elicitors SA and SN effectively enhanced RA production by in vitro cultured $H$. pectinata, and SN had a positive influence on growth parameters, biomass and accumulation of RA in $H$. pectinata seedlings.

\section{Conclusions}

Based on these findings, we conclude that the use of light quality and chemical elicitors represents a promising tool for the manipulation of morphological traits, increasing the accumulation of a metabolite of interest in $H$. pectinata. These methodologies can also contribute to diversity conservation strategies for $H$. pectinata. The use of elicitors is recommended in tissue culture to stimulate the production of a metabolite of interest on a larger scale, with a shorter cultivation time and without risk of extinction of the plant species. Therefore, this study may be useful as a theoretical basis and practical application as a contribution to better understanding the influence of these abiotic elicitors in in vitro cultured plant species.

\section{Supplementary Information}

Supplementary information $\left({ }^{1} \mathrm{H},{ }^{13} \mathrm{C}\right.$, HSQC, HMBC NMR and mass spectra of compound $\mathbf{1}$, spectral characteristics of the five fluorescent lights, HPLC-DAD chromatograms and UV spectra and statistical analysis tables) is available free of charge at http://jbcs.sbq.org.br as a PDF file. 


\section{Acknowledgments}

This study was financed in part by the Coordenação de Aperfeiçoamento de Pessoal de Nível Superior, Brazil (CAPES, Finance Code 001), Conselho Nacional de Desenvolvimento Científico e Tecnológico (CNPq, grant No. 305783/2012-2) and Fundação de Amparo à Pesquisa do Estado de São Paulo (FAPESP, grant No. 2011/00631-5). R. C. N. P. acknowledges Fundação de Amparo à Pesquisa do Estado de Goiás (FAPEG, grant No. 201310267000257) for the fellowship.

\section{References}

1. Harley, R. M.; Pastore, J. F. B.; Phytotaxa 2012, 58, 1.

2. Santos, P. O.; Costa, M. J. C.; Alves, J. A. B.; Nascimento, P. F. C.; Melo, D. L. F. M.; Barbosa Jr., A. M.; Trindade, R. C.; Quim. Nova 2008, 31, 1648.

3. Santos, K. P.; Sedano-Partida, M. D.; Sala-Carvalho, W. R.; Loureiro, B. O. S. J.; Silva-Luz, C. L.; Furlan, C. M.; Ind. Crops Prod. 2018, 112, 705.

4. Lisboa, A. C.; Mello, I. C.; Nunes, R. S.; dos Santos, M. A.; Antoniolli, A. R.; Marçal, R. M.; Cavalcanti, S. C.; Fitoterapia 2006, 77, 439.

5. Paixão, M. S.; Melo, M. S.; Oliveira, M. G.; Santana, M. T.; Lima, A. C.; Damascena, N. P.; Dias, A. S.; Araujo, B. S.; Estevam, C. S.; Botelho, M. A.; Quintans-Jr., L. J.; Phytother. Res. 2013, 27, 1328.

6. Basílio, I. J. L. D.; Agra, M. F.; Rocha, E. A.; Leal, C. K. A.; Abrantes, H. F.; Acta Farm. Bonaerense 2006, 25, 518.

7. McNeil, M.; Facey, P.; Porter, R.; Nat. Prod. Commun. 2011, 6,1775 .

8. Feitosa-Alcantara, R. B.; Blank, M. F. A.; Blank, A. F.; Nogueira, P. C. L.; Sampaio, T. S.; Nizio, D. A. C.; AlmeidaPereira, C. S.; Biosci. J. 2018, 34, 875.

9. Falcao, R. A.; do Nascimento, P. L.; de Souza, S. A.; da Silva, T. M.; de Queiroz, A. C.; da Matta, C. B.; Moreira, M. S.; Camara, C. A.; Silva, T. M.; Evidence-Based Complementary Altern. Med. 2013, 2013, DOI: 10.1155/2013/460613.

10. Falcão, R. E. A.; de Souza, S. A.; Camara, C. A.; Quintans, J. S. S.; Santos, P. L.; Correia, M. T. S.; Silva, T. M. S.; Lima, A. A. N.; Quintans-Junior, L. J.; Guimarães, A. G.; Rev. Bras. Farmacogn. 2016, 26, 203.

11. Shiga, T.; Shoji, K.; Shimada, H.; Hashida, S.; Goto, F.; Yoshihara, T.; Plant Biotechnol. 2009, 26, 255.

12. Lu, Y.; Foo, L.Y.; Phytochemistry 2002, 59, 117.

13. Picking, D.; Delgoda, R.; Boulogne, I.; Mitchell, S.; J. Ethnopharmacol. 2013, 147, 16.

14. Mello, M. B.; Botrel, P. P.; Teixeira, I. R. V.; Figueiredo, F. C.; Pinto, J. E. B. P.; Bertolucci, S. K. V.; Rev. Agrogeoambiental 2014, 6, 79 .
15. Chen, S.-L.; Yu, H.; Luo, H.-M.; Wu, Q.; Li, C.-F.; Steinmetz, A.; Chin. Med. 2016, 11, DOI: 10.1186/s13020-016-0108-7.

16. Idris, A.; Linatoc, C.; Fadzelly, M.; Bakar, A.; Ibrahim, Z. T.; Audu, Y.; J. Sci. Technol. 2018, 10, 32.

17. OuYang, F.; Mao, J.-F.; Wang, J.; Zhang, S.; Li, Y.; PLoS One 2015, 10, e0127896.

18. Batista, D. S.; Felipe, S. H. S.; Silva, T. D.; de Castro, K. M.; Mamedes-Rodrigues, T. C.; Miranda, N. A.; Ríos-Ríos, A. M.; Faria, D. V.; Fortini, E. A.; Chagas, K.; Torres-Silva, G.; Xavier, A.; Arencibia, A. D.; Otoni, W. C.; In Vitro Cell. Dev. Biol.: Plant 2018, 54, 195.

19. Karuppusamy, S.; J. Med. Plants Res. 2009, 3, 1222.

20. Ramirez-Estrada, K.; Vidal-Limon, H.; Hidalgo, D.; Moyano, E.; Golenioswki, M.; Cusidó, R. M.; Palazon, J.; Molecules 2016, 21, 182.

21. Giri, C. C.; Zaheer, M.; Plant Cell, Tissue Organ Cult. 2016, $126,1$.

22. Vitorino, L. C.; Silva, F. G.; Lima, W. C.; Soares, M. A.; Pedroso, R. C. N.; Silva, M. R.; Dias, H. J.; Crotti, A. E. M.; Silva, M. L. A.; Cunha, W. R.; Pauletti, P. M.; Januário, A. H.; Quim. Nova 2013, 36, 1014.

23. Pedroso, R. C. N.; Branquinho, N. A. A.; Hara, A. C. B. A. M.; Costa, A. C.; Silva, F. G.; Pimenta, L. P.; Silva, M. L. A.; Cunha, W. R.; Pauletti, P. M.; Januario, A. H.; Rev. Bras. Farmacogn. 2017, 27, 466.

24. Pedroso, R. C. N.; Branquinho, N. A. A.; Hara, A. C. B. A. M. F.; Silva, F. G.; Kellner Filho, L.; Silva, M. L. A.; Cunha, W. R.; Pauletti, P. M.; Januário, A. H.; Cienc. Rural 2019, 49, e20180278.

25. Murashige, T.; Skoog, F. A.; Plant Physiol. 1962, 15, 473.

26. Bernardes, W. A.; Lucarini, R.; Tozatti, M. G.; Souza, M. G.; Silva, M. L.; Filho, A. A.; Martins, C. H.; Crotti, A. E.; Pauletti, P. M.; Groppo, M.; Cunha, W. R.; Chem. Biodiversity 2010, 7, 1835.

27. Moharram, F. A.; Marzouk, M. S.; El-Shenawy, S. M.; Gaara, A. H.; El Kady, W. M.; J. Pharm. Pharmacol. 2012, 64, 1678.

28. Software R, version 3.5.2; R Development Core Team, Vienna, Austria, 2018.

29. Sigma Plot ${ }^{\circledR} 11.0$; Systat Software, Inc., San Jose, CA, USA, 2008.

30. Li, C.-X.; Dong, R.-Q.; Chang, S.-X.; Wang, L.-Z.; Rehman, M. K.-U.; Tao, J.-M.; Front. Plant Sci. 2017, 8, DOI: 10.3389/ fpls.2017.00078.

31. Huché-Thélier, L.; Crespel, L.; Gourrierec, J. L.; Morel, P.; Sakr, S.; Leduc, N.; Environ. Exp. Bot. 2016, 121, 22.

32. Warpeha, K. M.; Montgomery, M. L.; Environ. Exp. Bot. 2016, $121,56$.

33. Hoang, H. H.; Sechet, J.; Bailly, C.; Leymarie, J.; Corbineau, F.; Plant, Cell Environ. 2014, 37, 1393.

34. Dias, M. I.; Sousa, M. J.; Alves, R. C.; Ferreira, I. C. F. R.; Ind. Crops Prod. 2016, 82, 9. 
35. Stagnari, F.; Mattia, C. D.; Galieni, A.; Santarelli, V.; D’Egidio, S.; Pagnania, G.; Pisante, M.; Ind. Crops Prod. 2018, 122, 277.

36. Szopa, A.; Starzec, A.; Ekiert, H.; J. Photochem. Photobiol., B 2018, 179, 91 .

37. Abedini, A.; Roumy, V.; Mahieux, S.; Biabiany, M.; StandaertVitse, A.; Rivière, C.; Sahpaz, S.; Bailleul, F.; Neut, C.; Hennebelle, T.; Evidence-Based Complementary Altern. Med. 2013, DOI: 10.1155/2013/604536.
38. Kumar, V.; Parvatam, G.; Ravishankar, G. A.; Electron. J. Biotechnol. 2009, 12, DOI: 10.2225/vol12-issue2-fulltext-1.

39. Li, X.; Guo, H.; Qi, Y.; Liu, H.; Zhang, X.; Ma, P.; Liang, Z.; Dong, J.; Plant Cell, Tissue Organ Cult. 2016, 126, 333.

40. Park, W. T.; Arasu, M. V.; Al-Dhabi, N. A.; Yeo, S. K.; Jeon, J.; Park, J. S.; Lee, S. Y.; Park, S. U.; Molecules 2016, 21, 426.

Submitted: February 18, 2019 Published online: July 15, 2019 